\title{
Kolonialistiset välitilat Pienen pimeyden kuukaudessa
}

Artikkelissa tarkastellaan nenetsikirjailija Vasili Ledkovin romaania Pienen pimeän kuukausi (Mesjats maloi temnoty), joka on historiallinen, porojen kollektivisoinnista 1920- ja 30-lukujen Nenetsien kansallisessa piirikunnassa kertova teos. Romaania tulkitaan kyläproosan keinoja ja keskustelutilaa hyödyntävänä tekstinä, joka nostaa esiin porojen omistamiseen ja inmisen ja poron vuorovaikutukseen tulleiden muutosten aiheuttamia ristiriitoja sekä kollektivisointiin liittyvää väkivaltaa. Lukutapaa luonnehtii jälkikolonialistinen ote, jossa painottuu vähintään kahdenlaisten tulkintojen yhtäaikainen läsnäolo ja niiden limittyminen toisiinsa. Analyysissä keskitytään tekemään ymmärrettäväksi poron ja ihmisen välistä suhdetta poropaimentolaiskäytänteissä ja tuodaan esiin, miten romaanin hahmojen erilaiset tavat toimia heijastavat nenetsien konventioita tai asettuvat niitä vastaan. Samalla osoitetaan, että teksti tuottaa myös sosialistisen realismin ja neuvostoliittolaisen kyläproosan perinteen mukaisia mielikuvia, ja pohditaan, miten nämä ovat osa romaanin tarjoamaa kriittistä katsetta nenetsien menneisyyteen.

Karina Lukin

Venäjän ja Länsi-Siperian arktisilla alueilla elävien nenetsien historiassa porojen saattaminen kolhoosien yhteisomistukseen on yksi väkivaltaisimmista ja vaietuimmista menneisyyteen liittyvistä aiheista (esim. Golovnev \& Osherenko 1999, 68-93). Kollektivisointiin kietoutuu vaikeita nenetsiyhteisöjen sisäisiä sosiaalisia, kulttuurisia ja taloudellisia jännitteitä. Se kiinnitti tundralla liikkuvaa elämäntapaa harjoittaneet ihmiset neuvostoyhteiskunnan arkisiin käytänteisiin, jotka mursivat monia vakiintuneita tapoja. 1930-luvun väkivaltaisuuksien jälkeen muutokset ajattelutavoissa ja käytänteissä tapahtuivat hitaasti, mutta vääjäämättä. Vaikka nenetsitkin omaksuivat puolueen ja keskuskomitean propagoimia ajattelun malleja, porojen omistukseen liittyvät kysymykset jäivät vähintäänkin avoimiksi. Vasili Nikolajevitš Ledkovin (1933-2002) romaani Pienen pimeyden kuukausi (Mesjats maloi temnoty, 1973) 
palasi pohtimaan kollektivisaatiota 1970-luvun kirjallisessa kontekstissa, jossa menneisyyden kriittinenkin reflektointi oli mahdollista.

Romaanin yhtenä keskeisenä juonilinjana on kahden paljon poroja omistavan nenetsin porojen siirtyminen perusteilla olevan kolhoosin omistukseen. Romaanissaan Ledkov käsittelee kolhoosien perustamiseen ja kehittämiseen liittyviä aiheita laajemmin ihmisen ja eläimen välisten suhteiden kautta, mutta keskityn tässä artikkelissa erityisesti poron ja ihmisen suhteen käsittelyyn. Pohdin myös, miten Ledkovin romaani hyödyntää kyläproosan (derenvenskaja proza) poeettisia keinoja. Tulkintani on jälkikolonialistista ja lähestymistavalleni on keskeistä monien tulkintamallien samanaikaisen läsnäolon ja niiden synnyttämän jännitteen tunnistaminen. Romaani mahdollistaa porojen käsitteellistämisen omaisuutena tai pääomana, mikä on mahdotonta, jos tekstiä tulkitaan nenetsien poropaimentolaisessa kehyksessä, jossa ihmiset ja ei-inhimilliset toimijat asettuvat toistensa kanssa vastavuoroisiin suhteisiin. Tulkintojen väliin syntyvää jännitettä kutsutaan tässä artikkelissa "välitilaksi". Se on monia kulttuurisia malleja yhdistelevissä hybrideissä kirjallisuuksissa kirjallisuudentutkija Homi Bhabhan mukaan vääjäämätön tilanne, joka paljastaa yhtäältä kulttuuristen mallien väliset hierarkiat, mutta toisaalta antaa mahdollisuuden kiistää ne (Bhabha 1994, 5-6).

Erityisesti stalinistisessa kuvastossa arktinen alue kerrottiin keskuksen vastakohdaksi, joka muovattiin sosialististen sankareiden toiminnassa ja teknologian avustuksella osaksi Neuvostoliittoa (McCannon 1998, 81-109; Frank 2010; 2017). Neuvostokuvasto varioi aiempia pohjoisen mielikuvia, joissa Venäjä on sekä vihamielisen ja karun pohjoisen valloittaja että pohjoiseen identifioituva, sen erikoisolosuhteisiin hyvin sopeutunut toimija (Boele 1996, 17-47; 2016). Alkuperäiskansojen asema näissä kuvastoissa on usein marginaalinen, ja tyypillisesti, mikäli heidät mainitaan, he lankeavat valloituksen ja modernisaation kohteiksi siinä missä arktinen luontokin. 1930-luvun nenetsikirjallisuus uusinsi mielikuvaa modernisaation ja uudistusten tarpeesta. 1960-luvulta alkaen uudelleen virinnyt nenetsikirjallisuus näyttää tunnistavan valloituksen ja modernisaation eteläiset diskurssit, mutta tuovan niiden rinnalle pohjoisen ja alkuperäiskansan oman näkökulman. Näiden huomioiden lisäksi artikkeli on innoittunut myös viimeaikaisista keskusteluista, joissa on käsitelty kirjallisuuden tapoja kuvata ihmistä ja ei-inhimillistä ympäristöä (esim. Lummaa 2010; Rojola 2015). Ympäristöön keskittyvän kirjallisuustieteen kiinnostuksen painopiste on ollut etelässä ja Neuvostoliiton ulkopuolella (ks. kuitenkin Kuikka 2019; Perkiömäki 2018), ja tämä artikkeli laventaa erilaisten olioiden vuorovaikutuksen tutkimusta neuvostopohjoiseen. Hyödynnän artikkelissa myös viime aikoina Siperian alkuperäiskansojen poronhoidoista tehtyjä tulkintoja, jotka käyvät vuoropuhelua posthumanistisen tutkimusperinteen kanssa.

\section{Vasili Ledkov ja Pienen pimeyden kuukausi}

Vasili Ledkov on nenetsikirjailija, jonka ura on kovin tavanomainen neuvostoliittolaisen alkuperäiskansakirjailijan polku: hän opiskeli Leningradin Pohjoisten kansojen instituutissa ja palasi sieltä kotiseudulleen, Nenetsien autonomisessa piirikunnassa sijaitsevaan Varandeihin liikunnanopettajaksi ja sisäoppilaitoksen lastenhoitajaksi vuonna 1959. Hän työskenteli myös paikallislehti Njarjana Vynderin (suom. Punainen tundran asukas) toimituksessa. Ilmeisesti Ledkovin suorasukaisuus ja jyrkkyys aiheuttivat hänelle jatkuvia ongelmia: hän nosti julkisesti esiin sen, miten nenetsilapset häpesivät omaa identiteettiään eivätkä enää välttämättä osanneet äidinkieltään, minkä vuoksi hänet julistettiin "sosiaalisesti vaaralliseksi elementiksi" ja myöhemmin häntä syytettiin nationalismista. Ledkovilla oli suojelijoita, joiden ansiosta 
hän pystyi jatkamaan uraansa ja kouluttautumaan Moskovan Gorkin kirjallisuusinstituutin luennoilla. (Mihailov 1976, 29-30; Ponomarev 1982, 171-172; Ogryzko 2003, 29-30.) Kirjailijana Ledkov tunnetaan ennen kaikkea runoistaan, joita on julkaistu kymmenissä runokokoelmissa. Niin runoja kuin proosaakin on julkaistu pääosin venäjäksi, mutta esimerkiksi nyt huomion kohteena olevan romaanin Ledkov kirjoitti alun perin tundranenetsiksi. Teoksen on kääntänyt venäläinen kirjailija ja toimittaja Nikolai Pavlovitš Leontjev (1910-1984), eikä sen tundranenetsinkielistä versiota ole koskaan julkaistu.

Romaanissa on useita päähenkilöitä, joiden vaihtelevia ja usein väkivaltaisia, vallankumouksen ja Venäjän sisällissodan jälkeisiin vuosiin sijoittuvia kohtaloita siinä seurataan. Päähenkilöiden kohtalot liittyvät yhtäältä kahteen pororikkaaseen, paljon poroja omistaviin Odermaan ja Tesiin, joita romaanissa nimitetään kulakeiksi ja joiden saituutta, kieroutta ja sydämettömyyttä kerronta painottaa. Toisaalta romaanin tiet johtavat lähelle Jäämeren rantaa rakentuvaan Ison karhun tähdistö -nimiseen kolhoosiin (Sozvezdije bolšoi Medveditsy) ja Pejahan (Tšernaja) kylään, jossa Ledkov oli lapsuutensa elänyt. Oderma on jo romaanin alussa menettänyt muutamia paimeniaan kolhoosille, minkä vuoksi Tesi haluaa käyttää tilaisuutta hyväkseen ja varastaa Oderman huonolla paimennuksella olevia eli vaillinaisesti valvottuja poroja. Varuk Vas ja muutama muu paimen lähtevät Tesin käskystä porovarkaisiin, ja he onnistuvat viemään Odermalta useita satoja poroja. Samaan aikaan Oderma vangitaan taposta. Savane, Oderman leski, päätyy elämään yksin tundralla valtavan porotokan kanssa, mutta ajautuu traagisten käänteiden kautta poroineen kolhoosiin. Tesin leirissä paimenet haluavat itsenäistyä, sillä Tesin heille lupaama osuus mahdollistaisi itsenäisen elämän, mikäli porovarkaus onnistuu. Romaanissa kuvataan yksittäisten paimenten pohdintoja ja päätöksiä elää itsenäisesti tai liittyä kolhoosiin, ja paimen toisensa jälkeen päättää liittyä, mukaan lukien Tesin oma poika. Lopulta kolhoosiin liittymistä pakeneva ja kulakiksi julistettu Tesi tapetaan. Molempien pororikkaiden porot ovat päätyneet kolhoosin omistukseen. Romaanin kerronta fokalisoi kussakin lyhyessä luvussa yhteen henkilöön ja tapahtumaan: näin romaanissa liikutaan yhtäältä kolhoosin, toisaalta tundran eri toimijoiden välillä.

Romaanin paratekstit painottavat vallankumousta ja kollektiivisen talouden kehittymistä ja ohjaavat näin lukijan kiinnostuksen niihin: kirjan nimiösivulla romaanin kuvataan kertovan kolhoosien kehittämisestä Euroopan puoleisella tundralla sodanjälkeisinä vuosina, ja myöhemmin käsiteltävä romaanin alku kertoo vallankumouksesta ja sitä seuranneesta sisällissodasta. Tästä yhteiskunnallisesta korostuksesta huolimatta Andrei Veter (2003, 26-27) on todennut, että romaanin keskeisteemoja ovat ennen kaikkea yhteisöllisyyteen, rakkauteen ja ystävyyteen kietoutuvat inhimilliset valinnat: kolhoosiin liittymistä tai liittymättömyyttä ei missään vaiheessa perustella poliittisilla syillä, vaan romaanin henkilöt vetoavat toistuvasti joko toiseen ihmiseen tai tunturin liikkuvaan ja vapaaseen elämäntapaan liittyviin tunteisiin ja haluun olla vuorovaikutuksessa toisten kanssa tai vastaavasti jäädä yksin. Veterin muutoin hyväksyttävä ihmiskeskeinen tulkinta ei tee oikeutta tavalle, jolla ei-inhimilliset eläimet esiintyvät romaanissa.

\section{Jälkikolonialistinen lukutapa ja kyläproosa}

Veterin tapaan ihmiskeskeisesti Pienen pimeyden kuukautta on tulkinnut myös Ledkovin kanssa Tšernajasta kotoisin oleva kirjallisuuskriitikko Aleksandr Mihailov. Molemmat tulkitsevat Ledkovia Venäjän pohjoisia kansoja edustavana nenetsikirjailijana ja osana nenetsikirjallisuutta, ja heidän lähestymistapansa tuovat esiin Venäjän vähemmistökirjallisuuksien 
tutkimukselle tyypillisen siiloutumisen: kunkin vähemmistön kirjallisuutta tutkitaan omana ilmiönään, mikä korostaa kulttuurisia erityispiirteitä (Kurki 2018, 36; Leiderman 2015). Nenetsien kirjallisuutta on tulkittu tyypillisesti osana pohjoisten kansojen kirjallisuutta, jolloin on korostettu kirjallisen tradition lyhytikäisyyttä, määrällistä niukkuutta (mladopismennaja literatura) tai palautumista suulliseen perinteeseen (Pošatajeva 1988, 105-108; Lagunova 2007, 14-36; Lukin 2020a). Samalla on jäänyt huomioimatta se ilmeinen seikka, että Neuvostoliitossa kirjailijat osallistuivat yhtenäiseen sosialistisen realismin tai kansainvälisen kirjallisuuden projektiin ja kirjoittivat, etenkin 1930-luvun jälkeen, yhä enenevissä määrin venäjäksi (myös Lagunova 2007, 7, 37; Leiderman 2015; Frank 2016; Kuikka 2019).

Välttääkseni vähemmistökirjallisuuden erillisyyden mielikuvan toisintamista tulkitsen Ledkovin romaania kulttuurien ja muiden neuvostoliittolaisten erontekojen kohtaamisen tilana. Tulkinta on jälkikolonialistista, ja hyödynnän ennen kaikkea Homi Bhabhan näkemyksiä kulttuurien kohtaamisesta ja tämän aiheuttamasta jatkuvasta hybridisyydestä. Bhabha tarkoittaa hybridisyydellä kulttuurien kohtaamisessa syntyviä erontekoja ja niiden väliin syntyviä jännitteisiä suhteita ja tiloja. Bhabha on toistuvasti kehottanut kiinnittämään huomiota kulttuurierojen väliin syntyviin välitiloihin, sillä niissä ei uusinneta hallitsevia näkemyksiä, vaan neuvotellaan niistä (Bhabha 1994, 36-39, 54-56). Kolonialistissa konteksteissa on tyypillistä, että hallitseva ryhmä oikeuttaa toimintansa arvottamalla itseään myönteisemmin kuin toista. Esimerkiksi paimentolaista poronhoitoa nimitetään jälkeenjääneeksi elämäntavaksi, jonka uudistaminen modernisoisi nenetsien elämän ja tuottaisi ennenkuulumatonta onnea. Kun nenetsikirjailija kuvaa romaanissaan sekä paimentolaiselämää eläviä poronhoitajia että niitä ajatuksia ja tapahtumasarjoja, joita neuvostouudistuksista seuraa, romaanissa kohtaa kaksi erilaista näkemystä poronhoidosta - hallitseva, neuvostouudistukset oikeuttava ja nenetsien poropaimentolaiselämään ja -kulttuuriin perustuva. Lähtökohtani on, että sosialistinen realismi ja sen ympärille kehittynyt monikansallinen kirjallisuusprojekti oli paitsi itse jatkuvasti muutoksessa, myös Bhabhan kuvaaman kaltainen hybridisyyksille otollinen kirjallinen tila. Viittaan tällä siihen, että kirjailijoita kannustettiin kuvaamaan omaa ja paikallista kulttuuriaan, mutta asettamaan se neuvostokehyksiin. Näin hybridisyys oli kirjattu projektin osaksi.

1930-luvun nenetsikirjallisuudessa oman kulttuurin kuvaus noudatteli hyvin kaavamaisia linjoja, mutta tuotti toisinaan myös jälkikolonialistisen kaltaista pohdintaa. Pääosin se edusti sosialismin mukaista anti-imperialismia, jonka puitteissa osoitettiin tsaarinaikaisen Venäjän sortotoimiin. (Lukin 2020b; Kuikka ja Lukin 2020.) Ledkovin teoksen perspektiivi on historiallisesti laajempi, sillä siinä pohditaan myös neuvostoaikaisia muutoksia ja niiden vaikutuksia nenetsien elämään. Teos kritisoi ennen kaikkea poronhoidossa toteutettuja muutoksia ja rinnastuu näin kirjallisuuteen, jossa kritisoitiin Neuvostoliiton uudistuksia. Ledkov hyötyi kyläproosaliikkeestä ja tulkitsen analyysissäni, miten Ledkov hyödynsi sekä liikkeen luomaa kriittisen yhteiskuntakeskustelun tilaa että kirjallisuuden keinoja. Kylä- tai maaseutuproosaksi on nimitetty sosialistisen realismin kritiikistä ja uudistamisen tarpeesta syntynyttä venäläistä kirjallista liikehdintää, joka sai alkunsa suojasään vuosina 1950-luvulla. Tyypillistä kyläproosalle on kirjallisten teemojen ja keinojen vastakohtaisuus aiempaan, kolhoosiproosaksi nimitettyyn kirjallisuuteen: teokset keskittyivät vaatimattomaan venäläiseen kotielämään, kylään ja sitä ympäröivään luontoon, jotka loivat yhdessä kotiseudun, malaja rodinan vastakohtana aiemman kolhoosikirjallisuuden universaalille kehitykselle ja gigantismille, joita kyläproosassa haluttiin kritisoida. Kyläproosakirjallisuudessa korostuivat kolhoosikirjallisuuden monikansallisen, utooppisen tulevaisuuden sijasta menneisyys, katoavan nostalgia ja paikallisen kielen merkitys. (Gillespie 1991; Parthé 1992, 5-22; Leiderman \& 
Lipovetski 2003, 76). Esimerkiksi Parthé on maininnut kyläproosalle tyypillisiksi keinoiksi muun muassa 1) pyrkimyksen parempaan taiteelliseen ilmaisuun, mikä tulee esiin ennen kaikkea neuvostotunnuslauseiden ja kliseisten stalinististen mallien ja juonikaavojen välttelynä; 2) virallisen ja epävirallisen kielen erottamisen; 3) moniäänisyyden, joka tulee esiin erityisesti lukuisten fokalisointien ja sisäisen monologin välityksellä sekä 4) kulttuuristen aika- ja paikkakäsitysten esittämisen (Parthé 1992, 29-56).

Näiden temaattisten ja kerronnan keinovalikoimien havainnoinnin lisäksi analyysilleni on keskeistä tunnistaa Anna Razuvalovan (2015, 16-40) korostama yhteiskunnallisen keskustelun tila, jonka kyläproosakirjailijat loivat kirjallisuuteen ja laajemminkin yhteiskuntaan. Lähtökohtani on, että kyläproosaliike loi kirjalliselle areenalle sekä uudenlaisen ilmaisun että tematiikan alueen, jota muutkin kuin venäläiset neuvostokirjailijat, toisin sanottuna myös vähemmistöjen edustajat, hyödynsivät. Mahdollisuus käyttää aiemmin perifeerisiä tai tabuluonteisia symbolisia resursseja ja kieliä, jotka kiinnittyivät internationalismin ja kehityksen sijasta paikallisiin arvoihin ja perinteisiin (Razuvalova 2015, 32-33), lupasi paljon myös vähemmistökirjailijoille, jotka venäläisen talonpoikaiskulttuurin, kansanomaisuuden, perinteen ja menneisyyskuvan sijasta suuntasivat katseensa omaan perinteiseen elämäntapaansa ja siihen kietoutuviin käsityksiin. Ledkovia on kiehtonut mahdollisuus reflektoida paikallisella tasolla vallankumouksen aikaista menneisyyttä ja tuoda kriittisesti esiin siihen liittyviä laajoja ja syviä muutoksia traagisten kohtaloiden kautta. Hän ei ole hyödyntänyt yllä lueteltuja keinoja mekaanisesti, vaan romaanissa korostuu nenetsien kulttuurisista käytänteistä nousevien käsitysten ja mielikuvien kuvaaminen ja niiden asettaminen suhteeseen hallitsevien näkemysten ja ympäristöä esineellistävien uudistusten kanssa.

Venäläinen imperialismi ei ole merkittävällä tavalla päätynyt jälkikolonialistisen teoretisoinnin aiheeksi, minkä vuoksi korostan Turoman ja Waldsteinin (2013) tapaan venäläisten esimerkkien antia jälkikolonialistisen kirjallisuuden teorialle. Anti liittyy tässä artikkelissa siihen, miten ideologiat ja etniset ryhmät kulttuurisine piirteineen ja erilaisine historioineen limittyvät toisiinsa. Myöhäisneuvostoajalle oli tyypillistä, että jälkikolonialistisia kirjallisia ratkaisuja tekivät niin enemmistön kuin vähemmistöjenkin edustajat (Kukulin 2012). Neuvostoaikaisen kirjallisuuden - vähemmistökirjallisuuden ja kyläproosan - postkolonialistinen luonne tulee esiin juurettomuuden, hybridisyyden ja yhteiskunnallisen syrjäytymisen teemoissa, mikä on tyypillistä jälkikolonialistiselle kirjallisuudelle (Ashcroft et al. 2002, 17-27). Neuvostokirjallisuus ei kuitenkaan avoimesti tai radikaalisti haasta neuvostoaikaista identiteetti- tai valtapolitiikkaa. Jos kritiikkiä esiintyy, se kohdistuu menneisyyteen eikä johda sellaiseen avoimeen hallitsevan ja hallitun asemien kääntämiseen nurinkurin, mitä jälkikolonialistinen kirjallisuudentutkimus on kuvannut (Kukulin 2012). Kirjallisuus oli Neuvostoliitossa keskuksen ylläpitämä ja hallinnoima areena ja sen puitteissa keskusteleminen on edellyttänyt hyvin tunnettujen koodien osaamista ja niiden uusintamista (Clark 1981; Dobrenko 2001; myös Spivak 1993).

Venäläisen ja ei-venäläisen neuvostokirjallisuuden jälkikolonialistinen luonne ovat myös toisistaan poikkeavia. Vähemmistökirjailija ei julkaise venäläiskirjailijoista poiketen taidetta äidinkielellään, vaan venäjäksi, ja kertoo paikoista, elintavoista ja kulttuureista, jotka ovat enemmistölle vieraita. Vähemmistön kirjallisuudessa venäläisen kirjallisuuden arvostettu asema on usein läsnä yhtä aikaa vähemmistön omien ilmaisun konventioiden rinnalla (Leiderman 2015). Jos venäläisessä kyläproosassa voidaan nähdä jälkikolonialistisia elementtejä (Kukulin 2012), Ledkovin kyläproosaa hyödyntävä teos asettuu suhteessa siihen sekä rinnalle että poikkiteloin. Tämä johtuu siitä, että nenetsikirjailija purkaa sekä stalinistisia uudistuksia, 
joita on tarkasteltu kolonialistisina (Kukulin 2012; Razuvalova 2015, 527-531), että pidempiaikaisia venäläiseen imperialismiin kietoutuvia kolonialismin historioita. Siksi teoksessa on hiljaisuutta tai tulkinnan potentiaalia, joka jää helposti kuulematta (Lee 1974; Ashcroft et al. 2002, 73-79; 180-181.) Empire writes back -kirjassa vastaavaa tilannetta esitellään kaksiäänisyytenä (double entendre), tapana puhua plantaasiorjuuden kontekstissa niin, että isäntä ymmärsi viestin toisin kuin orjat. Harald Gaski taas on käyttänyt kaksoiskommunikaation ja kahdentuvien merkitysten käsitteitä saamelaisen kirjallisuuden yhteydessä. Hänen mukaansa joiun merkitykset perustuvat kaksitasoisten merkitysten välittämiseen niin, että "saamelaisyleisölle välitettiin yhdenlainen viesti, mikä erosi kovasti ulkopuolisille välittyvästä." (Gaski 1999, 8.) Gaski peräänkuuluttaa kulttuurin sisäisistä merkityksenannoista tehtävien tulkintojen tärkeyttä saamelaisen kirjallisuuden tutkimuksessa.

\section{Tundranenetsiä venäjäksi}

Pienen pimeyden kuukausi -romaanin alussa Ledkov kuvailee vallankumousta tavoilla, jotka asettavat nenetsit ja tundran eläimineen neuvostodiskurssien ulkopuolelle. Ledkov kuvaa tundraa ihmisten, eläinten ja lintujen maailmana, joka on toistunut vuorokausien ja vuodenaikojen syklissä ja johon kerran, ihmisten noustua toisiaan vastaan, ilmestyi sotilaita. Nenetsien osattomuus yhtäl̈tä ensimmäiseen maailmansotaan ja toisaalta vallankumousta seuranneeseen sisällissotaan tuodaan esiin ilmaisuilla, jotka välttävät aktiivista persoonaa. Ledkov asettaa tsaarinaikaisen Venäjän ja neuvostoaikaiset toimet rinnakkain, eikä pyri oikeuttamaan jälkimmäisiä ensimmäisillä. Sen sijaan teoksessa imperialismi hahmottuu pitkänä jatkumona ja esitetään, kuinka nenetsien suhde keskustaan on rakentunut tässä jatkumossa katkeamatta erilaisten sopeutumisten ja neuvottelujen varaan. Tällä tavalla jo romaanin alku yhtäältä hyötyy neuvostoaikaisista diskursseista, toisaalta kiistää niitä. Kerronnassa hyödynnetään mahdollisuutta kirjoittaa menneisyydestä ja kritisoida kolonialismia. Samalla romaanissa kuitenkin irtaudutaan kyläproosalle tyypillisestä neuvostokolonialismin ajatuksesta: se synnyttää kehyksen, jossa neuvostouudistukset ovat tulkittavissa yhdeksi venäläisten imperialistiseksi toimeksi pidemmällä imperialismin jatkumolla. Konkreettisesti kritiikki tulee esiin henkilöiden sisäisissä monologeissa, esimerkiksi kun Jegor pohtii mennyttä: "Eivätkö pahat ihmiset - venäläiset, Ižman komit ja pomorit - olekin jo kauan kolunneet tundraa; tappaneet nenetsejä, kohdelleet heidän vaimojaan väkivalloin, pilkanneet vanhuksia ja lapsia." (Ledkov 1979, 8.) Neuvostoaikainen pohjoisen haltuunotto on vain yksi esimerkki pohjoisen valloittamisen historiassa.

Vallankumouksen ja sitä seuranneiden uudistusten erityinen historia pohjoisessa on Pienen pimeyden kuukauden ilmeinen aihe. Aihe on sosialistisen realismin mukainen ja siihen viittaavat muutkin paratekstit nimeä lukuun ottamatta. Nimi viittaa romaanin alkua selvemmin pohjoisen erityiseen kokemukseen, sillä se viittaa venäjänkielisyydestään huolimatta keskukselle tuntemattomaan paikalliseen sanastoon. Nimi palautuu tundranenetsinkieliseen kuukaudennimeen ja sikäli vuosittain toistuvaan, sykliseen aikakäsitykseen. Vuodenkierto jakautuu nenetsien kansanomaisessa kuvastossa valoisan ja pimeän, lumisen ja verisen sekä kuuman ja kylmän vastakkainasetteluille. Pimeän ajan alku merkitsee kaamoksen, kylmyyden ja pakkasen lähestymistä, minkä vuoksi ajanjaksoa nimitetään pieneksi pimeydeksi tai pienen pimeyden kuuksi (TN njudja pevdja (jirii) $)^{1}$. Tätä seuraa suuri pimeys (TN ngarka pevdja (jirii)). Länsimaisessa kalenterissa jaksot sijoittuvat marras-joulukuulle. (Esim. Golovnev 1995, 300-303.) Romaanin nimi viittaa tähän aikaan, joka kerronnassa tulee määritellyksi ajan 
kierron aluksi. Poropaimentolaisten elämässä kylmyys, pimeys ja lumi merkitsevät hankalien ja työntäyteisten kesäkuukausien jälkeen mahdollisuutta työskennellä kodan luona tai kodassa ja lyhyempiä aikoja, kun porot ovat rauhallisempia ja pysyvät kotakylän lähistöllä. Pieneen pimeään liittyy siis paljon myönteisiä merkityksiä nenetsien elämäntavan kehyksessä. Sen lisäksi nimi avaa kurkistusaukon nenetsien ja porojen väliseen tai rinnakkaiseen olemisen tapaan ja vuodenkiertoon.

Poropaimentolaisuudesta nousevien tulkintojen rinnalla venäjänkielinen nimi huokuu pahaenteisyyttä, sillä pimeys (temnota) ei viittaa ainoastaan konkreettiseen, vaan myös metaforiseen, pimeyteen. Se voidaan liittää nenetsien jälkeenjääneeseen elämäntapaan ja leniniläisiin ajatuksiin modernisaatiosta valona. Nimi voisi viitata myös romaanin väkivaltaisiin tapahtumiin: useiden ihmisten kuolemaan, porojen siirtymiseen kolhoosin omistukseen ja sitä seuraavaan elämään, joka taas voisi saada nenetsien kalenterin mukaan nimekseen suuren pimeyden kuukauden. Romaanin nimi ei kuitenkaan avaudu täysin yllä hahmottelemassani poropaimentolaisessa kehyksessä, eikä sitä voi yksiselitteisesti liittää pimeän ja valoisan etenevään kulkuunkaan. Nimi on hyvä esimerkki Homi Bhabhan kuvaamasta ilmaisujen välisyydestä (interdiction), jossa tuotetaan tahattomasti tai tahallaan sellaisia totalitaarisia, usein vastakkainasetteluihin perustuvia mielikuvia kiistäviä näkymiä, jotka paljastavat kolonialistisen projektin erontekojen haurauden (Bhabha 1994, 127-129). Romaanissa kuvattu uuden ideologisen ajan alku sijoittuu nenetsien vuodenkierron uuteen aikaan, mutta tundranenetsinkielisen kuukauden nimen kääntäminen venäjäksi tuottaa ajan alulle kielteisen merkityksen, mitä ei voinut sanoa ääneen 1970-luvun Neuvostoliitossa. Nimi ei ole niinkään kiistämässä joko nenetsin- tai venäjänkielistä tulkintaa kuin osoittamassa niiden väliin, siihen, ettei selkeää erontekoa nenetsin- tai venäjänkielisen, poropaimentolaisen tai sosialistisen ilmauksen, aikakäsityksen tai tulkinnan välille voi tehdä, sillä ne liukuvat jatkuvasti toistensa lomaan.

Romaanin nimi on rinnakkainen poeettinen keino nenetsinkielisten paikannimien ja runsaan paikallisen, erityisesti poronhoitoon viittaavan sanaston käytön kanssa. Sitä voi pitää esimerkkinä Ledkovin tavasta viitata nenetsien omaan perinteeseen ja samalla luoda hybridi kuva paikallisen ja ylipaikallisen, nenetsien ja venäläisten näkökulmien limittäisyydestä. Haluan kiinnittää huomiota kahteen seikkaan romaanin nimessä. Ensinnäkin se poeettisena keinona seuraa kyläproosan strategioita ja tuo paikallisen, syklisen elämän malleja osaksi kerrontaa niin kuin kerronnan alkukin tekee (esim. Leiderman \& Lipovetski 2003, 71-72; Parthé 1992, 50). Toiseksi nimi itsessään on monitulkintainen: pohjoisen pimeyteen viittaava kuukauden nimi vihjaa mahdolliseen käännökseen ja venäjänkielisen ilmaisun aiheuttamiin hankaluuksiin ja sikäli välitilaan, jossa kaksi mahdollista tulkintaa on läsnä.

\section{Paimenet, rengit ja kulakit}

Kun Pienen pimeyden kuukausi siirtyy kertomaan aktiivisista nenetsitoimijoista, keskuksen ja periferian vastakkainasettelua peilataan nenetsien yhteisön sisäisten ristiriitojen kautta. Näin romaanin alussa kuvattu ulkopuolelta tuleva muutos ja passiiviset nenetsit jäävät taustalle. Tämän lisäksi kerronnassa painottuu nenetsien ja eläinten välinen vastavuoroinen oleminen tundralla ja siihen liittyvät kolhooseihin järjestymisen tuomat ongelmat. Erittelen tulevassa analyysissä ensin inhimillisiä toimijoita, minkä jälkeen pohdin heihin liittyviä poron toimijuuden vaihteluita. Niin yksityiskohdissa kuin romaanin juonen tasollakin toimijuuksien myötä kohtaavat nenetsien poronhoito konventioineen ja kollektivisaation taustalla olevat 
sosiaaliset kategoriat ja esineellistävä ympäristösuhde. Syntyy välitila, jota luonnehtii lopullisen tulkinnan epävarmuus ja jännitteisyys, kahdentuvat merkitykset.

Sosiaalisten kategorioiden jännitteisyys korostuu nimityksissä, joita Pienen pimeyden kuukauden hahmoista käytetään. Nimitykset ja niihin liittyvät hahmojen luonnehdinnat tuottavat vastakkainasetteluja nenetsiyhteisön sisälle. Pororikkaita Tesiä ja Odermaa luonnehditaan toistuvasti kielteisesti ja heitä nimitetään kulakeiksi. Paimenia taas nimitetään rengeiksi (batrak). Pororikkaita kuvataan ahneiksi, itsekkäiksi omaneduntavoittelijoiksi, joita näyttää kiinnostavan ainoastaan oman porotokan suuruus. He ovatkin romaanin hahmoista yksioikoisimpia ja vastaavat sosialistisen realismin perinteistä viholliskuvaa, jonka perusteella on voitu oikeuttaa neuvostouudistukset. Kulakin ja rengin sosiaaliset kategoriat ovat keskuksesta tai venäläisestä puheentavasta omaksuttuja käsitteitä. Niiden taustalla oleva vastakkainasettelu omistajan ja työläisen välillä ei asetu helposti nenetsien poronhoitoon liittyviin yhteisöllisiin luokitteluihin, joissa vastaavia toimijoita nimitettäisiin kotakylän isännäksi 'jerw' ja paimeneksi 'ti' pertja'. Nämä kategorianimitykset eivät tule romaanissa esiin, mutta poropaimentolaisessa tulkintakehyksessä ne ovat luontevammat sosiaalisten ryhmien kuvaamisen tavat. Niiden taustalla ei ole sellaista vastakkainasettelua kuin neuvostokuvastossa ja ne liittyvät vastavuoroisuuden ajatukseen, joka on keskeinen myös tulevassa porojen toimijuuden pohdinnassa: Nenetsien harjoittamaan suurporonhoitoon kuuluu keskeisenä ajatus tundralla elävien olioiden välisestä vastavuoroisuudesta. Vastavuoroisuus koskee niin ihmisiä, ei-inhimillisiä eläimiä kuin yliluonnollisia toimijoitakin ja se tarkoittaa toisen tarpeiden ymmärtämistä ja hyväksymistä. Käytännössä ajatus tulee esiin edellytyksenä auttaa, olla vieraanvarainen, ottaa vain oman tarpeen verran ja toimia joustavasti muiden tunturissa elävien toimia ennakoiden (esim. Stammler 2005, 83-91; Anderson 2017). Vastavuoroisuuteen ei kuulu ajatusta tasa-arvosta tai saumattomasta harmoniasta: nenetsiyhteisössä on taloudellisia ja sosiaalisia hierarkioita niin kuin missä tahansa yhteisössä ja elämä tunturissa voi olla vaikeaa ja raskasta. Rikkaiden velvollisuuksiin kuuluu vähemmän poroja omistavien tukeminen esimerkiksi niin, että köyhien porot laiduntavat kesäisin samassa tokassa rikkaan porojen kanssa. Vastaavasti köyhät poronhoitajat voivat pestautua paimeniksi enemmän poroja omistavalle tai esimerkiksi metsästystä voidaan harjoittaa yhdessä. (Tuisku 1999, 82-83; Stammler 2005, 83-84.)

Ledkov on käyttänyt kulakin ja rengin nimityksiä ja uusintanut hallitsevan tulkintakehyksen mukaista vastakkaisasettelun kuvastoa huolimatta siitä, että se ei sovellu yhteen ylläkuvatun yhteisökäsityksen kanssa. Kulakkien suhteen mielikuvat ovat järkähtämättömiä koko romaanin ajan, mutta renkien suhteen on toisin. Romaanin rengit eivät ole alistettuja ja alistuvia, minkä vuoksi vallankumousta ja sitä seuraavaa kollektivisaatiota edellyttänyt tilanne ei oikeuta neuvostouudistuksia, joiden taustalla oli ajatus epätasa-arvosta ja riistosta. Rengit osoittautuvat ennemminkin paimeniksi ja paimenten mielenmaisemaa ja toimintaa tuodaan vivahteikkaasti esiin esimerkiksi moraalisten pohdintojen kautta. Paimenen kategorialla viittaan porojen kanssa tundralla eläviin, itsenäisiä päätöksiä tekeviin miehiin. Heidän nimittämisensä rengiksi asettaa heidät sosialistisen realismin kuvastoon, mutta heidän toimintansa kertoo paimenen asenteesta. Asetelma on ristiriitainen ja se voidaan tulkita yhtäältä yksioikoisen neuvostokuvaston kritiikiksi ja toisaalta kolhoosissa elävien nenetsien uusien sosiaalisten kategorioiden ristiriitaisuuksien pohdinnaksi, välitilaksi.

Ajatuksiltaan ja toimiltaan vastakkain asettuvat Jegor, Oderman viimeinen paimen ja Varuk Vas, joka on Tesin paimenista vanhin. Jegorin hahmossa tiivistyy hyvän paimenen ideaali, mikä tulee esiin juuri ylläkuvatun vastavuoroisuuden periaatteiden kautta: 
Unisen Sula-joen rannoilla tiheä ja korkea pajukko piilotti viisituhantisen tokan. Sumu oli niin sakea, että sitä olisi voinut lyödä kirveellä. Läpipääsemättömässä harmaassa usvassa Jegorin reki lensi kuin taivaalla näkymätöntä vuorta kohden. Reen jyskeen ja koparoiden askelluksen kuullessaan tokassa olevat porot nostelivat levottomina päitään: ne olivat valmiita nelistämään paikoiltaan minä hetkenä hyvänsä. Korviaan höristellen ne haistelivat pitkään ilmaa ja lopulta rauhoittuivat ja alkoivat näykkiä harmaata, pakkasenpuremaa jäkälää. Räkkä ei nukkunut...Yön lämmin ja kostea ilma oli sille ihanteellinen. Pajukko humisi itikoiden näkymättömistä siivistä. Sääsket piirittivät porojen koipia, niiden pulleita kylkiä, nuoria karvapeitteisiä sarvia, joita kärsimyksen väsyttämät eläimet raaputtivat pakkasen taivuttamien pajunoksien ryhmyihin. Jegor ei alkanut tunkeutua lauman sekaan: sumussa pitäisi lyödä sataa tai kahta päätä ja niille voisi silloin jättää hyvästit. Räkkä ajaa poroja hyvinkin sata virstaa. Jos itse ajat kymmenisen matkaa, ajat ajoporosi loppuun ja itsesi puolikuoliaaksi, etkä palaudu millään. ${ }^{2}$ (Ledkov 1979, 8.)

Jegor katselee porotokkaa kääntein, joita voi luonnehtia poropaimentolaisuudelle konventionaalisiksi ja sisäinen monologi heijastelee paimenen ja porotokan välistä vuorovaikutusta. Nopeasti laumaa lähestyvä ajuri aiheuttaa poroissa levottomuutta, mutta ne tulkitsevat tutun paimenen liikkeet niin, että jatkavat ruokailuansa. Jegorin oma katse poroja kohtaan tuo esiin myötätuntoa, mutta myös järkeilyä, joka perustuu kokemukseen porojen kanssa toimimisesta: hermostuneen lauman keskelle ei kannata sumussa ajaa, mutta paimenen ei myöskään kannata väsyttää itseään paimentamalla tokkaa, jota räkkä jo muutoinkin liikuttelee. Jegorin ääni ei ole kiinnostunut porojen omistamisesta, varastamisesta, siirtämisestä, vaan siitä, miten porot reagoivat ja miten ne voivat. Hän ei halua kiusata tokkaa eikä turhaan väsyttää omia ajoporojaan, kuten ei itseäänkään. Porojen ja Jegorin toiminta ovat vuorovaikutteisessa suhteessa.

Varuk Vas on romaanin henkilöhahmoista vanhin ja kokenein tundralla liikkuja; hän on Tesille lojaali paimen, joka on valmis toteuttamaan isäntänsä antamat tehtävät kyseenalaistamatta. Toisaalta Varuk Vasia ajaa halu elää vapaana, oman kotakylän isäntänä, minkä vuoksi hän suostuu porovarkauteen, mutta ei ole halukas liittymään kolhoosiin. Varuk Vasin käyttäytymistä luonnehtii vastavuoroisuuden sijaan voimankäyttö ja väkivaltaisuus, ja hänen toimintansa romaanissa koostuu sarjasta erilaisia porovarkauksia, jotka taas asettuvat voimakkaasti nenetsien konventioita vastaan. Toistuvat ja toisiinsa ketjuuntuvat varkaudet kerrotaan tavoin, jotka korostavat ihmisten käyttämää valtaa ja voimaa, mutta muistuttavat tapahtumien jättämistä materiaalisista jäljistä. Esimerkiksi romaanin alkupuolella Tesin paimenet käyvät pitkän matkan varastaakseen toisen suuromistajan, Oderman, tokasta niin paljon poroja kuin pystyvät. Tesi saa taivuteltua paimenensa varkauteen lupaamalla näille kaksi kolmasosaa varastetuista poroista ja 30 omaansa. Käytännössä Tesi lupaa paimenille vapauden, mahdollisuuden itsenäistyä poronhoitajana. Varkaus kerrotaan Oderman poroja paimentavan Jegorin näkökulmasta:

Kolme nenetsiä tarttui Jegoriin ja raahasi hänet järven rannalle. Pian suopungilla reen päälle köytetty Jegor riippui rantapenkereen reunalla. Hän voisi tipahtaa rekineen järveen ja hukkua, jos vain yrittäisikin vapautua. Jos ei hukkuisi, hyttyset söisivät elävältä. Jegor näki, miten nenetsit lähtivät tokan luo, minkä jälkeen hän vielä pitkään kuuli huutoja, vihellyksiä ja poron koparoiden kumean ryskeen. Sitten tuli hiljaista. 
Jegor makasi reessä, katseli harsopilviä, jotka ennustivat sadetta, sitten kun häntä ei enää olisi. (Ledkov 1979, 14.)

Paimenen sitominen on tässä yhtä väkivaltainen teko kuin porojen erottaminen ja ajaminen Tesin porojen joukkoon: molemmat ovat toisen vapauden riistämistä, yhtäältä liikkumisen rajoittamista, toisaalta siihen pakottamista. Varkauden niukka kerronta nostaa esiin paimenten huudot ja vihellykset, joilla poroja ohjataan ja painostetaan liikkeelle, porojen liikkumisen pistävän äänimaiseman ja sitä seuraavan hiljaisuuden sekä köytetyn paimenen kyvyttömyyden vapautua. Lakonisuus korostaa väkivallan ja porovarkauden nopeutta ja samalla sen taakseen jättämää tyhjyyttä ja hiljaisuutta. Varasjoukko ei toimi vastavuoroisessa, toisen tarpeet huomioon ottavassa vuorovaikutuksessa porojen eikä niiden paimenen kanssa. On huomattavaa, miten kerronta asettuu vastakkain yhtäältä Jegorin toiminnan kuvauksen ja toisaalta myöhemmän Varuk Vasin kuvauksen kanssa, joka keskittyy omaehtoisuuden ja vapauden kaipuuseen.

Porojen ja paimenen vastavuoroisuutta ei korosteta romaanissa siitä erityisesti kertomalla, mutta se tulee esiin yllä kuvattujen vastakohtaisten toimintamallien välityksellä. Poron toimijuus rakentuu näissä kohtauksissa usein sisäisessä monologissa, joka kuvaa paimenen järkeilyä. Järkeilyssä korostuu sopeutuminen siihen, mitä paimen ajattelee porojen tekevän, toisin sanoen millaisen poron toimijuuden hän hahmottaa. Jos porot ovat levottomia, niitä on turhaa alkaa ajaa, sillä ne saattaisivat hajaantua - kuten Jegor järkeilee yllä. Kun taas Varuk Vas joukkoineen haluaa varastaa, porojen mielihaluja ei pohdita, vaan ne ajetaan kovin äänin ja uhkaavin liikkein eroon omasta tokastaan. Ensimmäisessä kohtauksessa korostuu vastavuoroisuus, toisessa väkivalta.

Sitoessaan romaanin teeman paitsi kolhoosiin ja sen rakentamiseen sekä vuorovaikutukseen porojen kanssa, Ledkov on hyödyntänyt kyläproosaliikkeen avaaman kriittisen historiallisen keskustelun tilaa ja kiinnittynyt perinteeseen, jossa kuvataan paikallista elinkeinomaisemaa ja suhdetta eläimiin (Razuvalova 2015; Parthé 1992, 7). Paikallisen maiseman ja nenetsien elinkeinon esiintuomista ei voida pitää vain kansallis- tai paikallisvärin (kolorit) kirjoittamisena sosialistisen realismin kehyksiin, vaan poronhoitoon pureutuva teksti pohtii uudistuksiin keskeisesti liittyviä ja nenetsejä askarruttaneita ongelmia. Näin Ledkovin päämääränä on ollut myös kyläproosakirjailijoiden pyrkimys kirjoittaa taiteellisesti korkeatasoisempia romaaneja kiinnittymättä kaavamaisiin stalinistisiin kerronnan tapoihin. Olennaista on myös se, että paimentolaiselämää elävien ihmisten suhde eläimiin on toisenlainen kuin vaikkapa kyläproosan agraarisessa kontekstissa sekä se, että Ledkov käsittelee ihmisten ja eläinten suhdetta eri ihmisiin fokalisoiden: syntyy monitahoinen kuva eri-ikäisten, eri sukupuolia edustavien ja eri asemissa olevien ihmisten suhteista ei-inhimillisiin toimijoihin. Olen tuonut näitä kuvia esiin Jegorin ja Varuk Vasin vastakkainasettelussa.

Luodessaan kuvaa nenetsiyhteisöstä ja sen yksittäisistä toimijoista romaani eroaa merkittävimmällä tavalla kyläproosasta, jonka kuvaukset pohjoisista alkuperäiskansoista ovat kaavamaisia ja ulkoapäin syntyneitä. Slezkine (1994, 292-293) on nimennyt "pitkäksi matkaksi" (Long Journey) yleisen neuvostoliittolaisen juonikaavan, jossa tsaarinaikaisella Venäjällä alistettua ja jälkeenjäänyttä elämää elävä alkuperäiskansan edustaja siirtyy hitaasti kohti sivistystä ja sosialismia (ks. myös Nichols 1993). Razuvalova (2015, 517-549) on osoittanut, että etenkin varhaiset kyläproosan siperialaistekstit ovat tuottaneet tällaisia kuvauksia, mutta 1970-luvulla Viktor Astafejevin ja Valentin Rasputinin romaaneissa esiintyy myös alistettuja modernisaation uhreja ja muinaisuuden viisautta ja perinnettä edustavia alkupe- 
räiskansahahmoja, kuten Osku, Timkoul tai ryhmänä esiintyvät tofalarit. Näihin allegorisiin hahmoihin verrattuna Pienen pimeyden kuukaudessa esiintyy omassa toimintaympäristössään sen ajattelumalleihin palautuvia päätöksiä tekeviä nenetsejä, joiden kuva asettuu kyläproosan sisäisen kolonialismin logiikkaa noudattavien alkuperäiskansahahmojen passiivisuutta ja toiseutta vastaan. Ero on merkittävä, sillä se kiistää myös vanhempia, tsaarinaikaisia kuvastoja ja asettaa romaanin näkökulman pohjoiseksi - toisin sanottuna romaanissa ei kerrota pohjoista etelästä käsin.

Aiemmissa Ledkov-tulkinnoissa nenetsien toimijuus on liitetty "pitkän matkan" kaltaiseen kehityksen kehykseen. Aleksandr Mihailov on lyhyessä kritiikissään todennut, että Pienen pimeyden kuukauden alun porovarkauskohtaus täyttää ainoastaan paikallisen tehtävän eli osoittaa "miten syvältä pimeydestä ja julmuudesta tundran ihmiset on saatettu tähän: vailla oikeutta olleet, alistetut, kaltoin kohdellut sekä ankarasti hyväksikäytetyt paimenet ovat valmiita elämään isäntänsä kanssa yksin toivon varassa ja käytännössä tuomitsevat kuolemaan samanlaisen, isäntänsä omaisuutta suojelevan paimenen.” (Mihailov 1976, 32.) Mihailovin lukutapa on oman aikansa hallitsevan tulkintamallin mukainen ja se muistuttaa myös ylläkuvattuja kyläproosan alkuperäiskansakuvia: tulkinnassa korostuu historiallinen materialismi ja nenetsien kulttuurinen ja taloudellinen jälkeenjääneisyys sekä edistys, joka lopulta toteutuisi juuri kolhoosissa. Nenetsien paikallisista ja kulttuurisista käytänteistä kumpuava toimijuus ja suhde poroihin onkin tulkittavissa vain, jos tuntee poronhoitoon liittyviä ajattelumalleja. Tulkinnan kannalta kyseessä on kaksiäänisyys, joka on yhtäältä osa mitä tahansa hybridiä ilmaisua. Näyttää siltä, että kaksiäänisyys tai toisen äänen olemassaolo on jäänyt venäläisiltä tulkitsijoilta tyystin huomaamatta.

\section{Porojen toimijuus}

Edellisen luvun esimerkeissä kuvattiin sitä, miten ihminen toiminnassaan ottaa porojen näkökulman huomioon tai miten hän voi halutessaan käyttää voimaansa myös poroja vastaan. Myöhemmin romaanissa Varuk Vasin kohtalo näyttää murentuvan siihen, että hän unohtaa porojen toimijuuden. Tesiltä varastamiensa porojen avulla itsenäistyneen Varuk Vasin leiriin saapuu romaanin loppuvaiheilla Martyn, Tesin poika, joka haluaisi mennä naimisiin Varuk Vasin tyttären, Sernen, kanssa. Varuk Vas on jo aiemmin kieltäytynyt liitosta vedoten nuorten erilaisiin sosiaalisiin asemiin. Nyt avioliiton estävät porot, joiden tavanomaisesti pitäisi toimia avioliiton ja ystävyyden solmimisen välineinä:

Hänen tokassaan on omien porojen lisäksi Tesin laumasta varastettuja. Martynin ei tarvitse kuin vilkaista tokkaa, niin heti paljastuu että hän, Varuk Vas, on varas. Ja sen ymmärrettyään Martyn ei varmasti vaikenisi. Sen jälkeen voisi odottaa muilta halveksuntaa, Tesiltä kostotoimia: hän ei jättäisi sellaisesta rankaisematta. (Ledkov 1979, 49.)

Lainauksen sisäinen monologi paljastaa, miten vaikeisiin tilanteisiin porojen varastaminen johtaa. Tämä palautuu inhimillisen vastavuoroisuuden periaatteisiin ja siitä seuraavaan poron toimijuuteen. Porojen roolin tulkitseminen edellyttää, että ymmärtää poron aseman paimentolaisten ajattelutavoissa: Porot ovat poropaimentolaisen pääasiallinen omaisuus ja ratkaiseva tekijä omaehtoisen elämän ehtojen ja liikkeen määrittäjänä. Ne ovat liikkumisen väline, minkä lisäksi porosta saadaan raaka-aineet ravintoon, vaatetukseen ja asujaimistoon. Mutta näiden päällisin puolin ilmeisten tosiasioiden lisäksi poroilla on merkittävä rooli eri- 
laisten sosiaalisten suhteiden luomisessa joko auttamisen kautta tai yksinkertaisesti lahjana, avioliittojen järjestelyssä tai uhrina. (Stammler 2005, 170-183.) Ihmisen ja porojen suhteeseen kuuluu väistämättä vastavuoroisuus, mahdollisuus ja pyrkimys luoda sellaisia tiloja, joissa molemmat voivat tulla paikalle ja hyötyä (Stammler 2010; Davydov 2014; Anderson 2014; Anderson et al. 2017; Stépanoff et al. 2017). Yllä analysoitu Jegorin paimennusta käsittelevä kohtaus heijasteli tällaista suhdetta.

Varuk Vasin monologi perustuu ajatukseen tunnistamisesta. Nenetsien poropaimentolaiseen diskurssiin kuuluu puheen tapa, jonka mukaan paimenet ja omistajat tunnistavat poronsa ilman korvamerkkejäkin, mutta viimeistään korvamerkit paljastavat eläinten alkuperän. Korvamerkkejä tarkastellaan porojen harhauduttua toiseen laumaan, mutta vieras korvamerkki omassa tokassa voisi kertoa myös siitä, että poro on saatu joltain lahjaksi. Nyt tokassa olevat lukuisat porot paljastaisivat Varuk Vasin vilpillisyyden, niiden toimijuus perustuu niiden muuttumattomuuteen - ne on väkivalloin siirretty laumasta toiseen ja ilmaisevat sen olemuksellaan. Poro ei ole kasvotonta pääomaa.

Varuk Vasin suhteen romaanissa pohditaan, mahdollistaako porovarkaus itsenäistä elämää ilman että toimisi jonkun tai jonkin paimenena, toisin sanottuna sitä, voiko porojen omistajuutta siirtää väkivalloin. Kysymykseen vapaudesta, jonka porot mahdollistavat, kiteytyy Ledkovin romaanin keskeinen kahdentuva tulkinta. Hallitsevan kehyksen mukaisessa tulkinnassa paimenet, kalastajat ja metsästäjät ovat kaikki automaattisesti vapaita kolhoosissa. Tästä eroavassa tulkinnassa, poropaimentolaisuudessa elävän paimenen näkökulmasta kolhoosi on vain uusi isäntä, mutta se näyttää vaativan luopumista tavanomaisista poron omistamiseen liittyvistä käytänteistä, mikä taas herättää kysymyksiä ihmisten välisestä sekä ihmisten ja porojen välisestä suhteesta. Romaanissa Varuk Vasin toiminta asettuu analogiseen suhteeseen kolhoosin toimien kanssa, mikä antaa mahdollisuuden kysyä, voidaanko porojen pakkolunastuksia kolhoosiin pitää varkautena. Näin on etenkin, koska suurin osa poroista päätyy kolhoosiin omistukseen jonkinlaisen väkivallan myötä. Täten Mihailovin toissijaiseksi tulkitsema tapahtuma asettuu romaanin keskiöön, sillä kolhoositoiminnan kehittämisessä pohjoisessa on ollut kyse juuri porojen lunastuksista ja omistussuhteiden muutoksista. Romaani tarjoaa mahdollisuuden tarkastella myös Odermaa ja Tesiä samankaltaisina suuromistajina kuin kolhoosi ja romaanin loppuratkaisussa niin Tesin kuin Odermankin porot ovat siirtyneet kolhoosin omistukseen.

Porojen siirtymistä omistajalta toiselle ja lopulta kolhoosiin voidaan tulkita tuotantovälineiden ja pääoman liikutteluna, mikä on tyypillistä hallitsevalle tulkinnalle. Tällöin porovarkaus ei sinänsä näyttäydy muuta kuin yhtenä omistajanvaihdoksena ja heijastaa rikkaiden kulakkien ahneutta. Tämä toistuu Tesin käskyissä ja lupauksissa, jotka eivät noudata poropaimentolaisuuteen liittyviä konventionaalisia periaatteita, vaan päinvastaisesti niille edellyttävät rikosta ja sääntöjen rikkomista. Tässä kehyksessä kolhoosi edustaisi modernia, rationaalista ja tasapuolista ratkaisua, kun taas vanhat pororikkaat kuvataan hallitsevan mallin mukaan kielteisesti. Poropaimentolaisesta näkökulmasta kolhoosiin liittyminen johti vääjäämättä konventioiden rikkomiseen tai niistä joustamiseen ja porovarkaus, sen väkivaltaisuus ja siitä seuraava epävarmuus ja onnettomuudet kuvaavat tätä vaikeaa prosessia.

Romaanissa hallitseva ja nenetsien poropaimentolaisuuden käytännöistä kumpuava tulkinta nivoutuvat toisiinsa Bhabhan kuvaileman hybridin lailla, mistä johtuen niiden välissä käydään neuvottelua. Hallitseva tulkinta on avoimesti ja selkeästi luettavissa, mutta sen kanssa neuvottelevaa poropaimentolaista tulkintaa voi pitää kahdentuvana eli se avautuu esiin epäsuorasti kirjoitettuna. Tämä ylläkuvattuun Jegorin ja Varuk Vasin vastakkainasetteluun 
sekä paimenen, rengin, kotakylän isännän ja kulakin kategorioiden ristiriitaan liittyvä tulkinta kiinnittyy porojen ja ihmisten väliseen suhteeseen. Paitsi että kolhoosiin liitetyt porot tulkitaan tässä mallissa väkivalloin otetuiksi, ne kantavat mukanaan myös merkkiä eli tietoa edellisestä omistajasta. Väkivaltaisen anastamisen tausta ja nenetsiyhteiskunnan entiset eronteot ovat poroissa läsnä ja näkyvillä: porojen toimijuus on niiden muuttumattomuudessa. Romaani ei kuvaa tätä suoraan kolhoosin yhteydessä, mutta muistuttaa tästä Varuk Vasin avulla.

Porojen yksipuolinen käsitteellistäminen vain pääomaksi on piilottanut romaanin nenetsilähtöisen tulkinnan heidän kulttuuriinsa perehtymättömiltä ulkopuolisilta. Molemmat tulkinnat ovat tehtävissä ja kahdentuvat ja limittyvät toisiinsa hankalalla tavalla. Porojen pakkosiirto kolhoosin omaisuudeksi on jyrkässä ristiriidassa poropaimentolaisen omistamisen ja porosuhteen kanssa ja se, miten porot loppujen lopuksi siirtyivät kolhoosin poroiksi on ollut keskeinen neuvostovaltaa legitimoiva kysymys myös käytännössä, ei vain kaunokirjallisuudessa (Sergejev 1955; Tuisku 1999, 82-86; Golovnev \& Osherenko 1999, 77-93.) Teema oli neuvostoaikoina myös nenetsien julkisten keskustelujen ja muisteluiden tuolla puolen. Poronhoidon kollektivisointi oli väkivaltainen ja traumaattinen tapahtumien sarja, jossa kunkin piti lopulta sijoittua osaksi kolhoosia. (Golovnev \& Osherenko 1999, 81-93; Tuisku 1999, 84; Vallikivi 2005; Lukin 2011, 33-38, 51; Laptander 2014.) Sosialistisen realismin selkeitä rakenteita ja tulkintamahdollisuuksia sekä paikallisia elementtejä edellyttänyt kehys on mahdollistanut aiheiden yhdistämisen ja niiden käsittelyn. Merkittävää on, että Ledkov ei ole kirjoittanut yksinkertaiselle vastakkainasettelulle perustuvaa juonta, vaan luonut kulakin ja rengin vastinparin rinnalle hahmoja, jotka eivät sijoitu kumpaankaan kategoriaan. Lisäksi Ledkov on rakentanut vastakkainasettelut nenetsiyhteisön sisällä, jossa nenetsien erilaiset näkemykset ovat kohdanneet toisensa myös käytännössä. Toisin sanottuna Ledkov kirjoittaa niin eronteot kuin niiden välillä käytävän keskustelunkin nenetsiyhteisön sisälle. Porot ovat yhtä ankaria tässä suhteessa, sillä ne ovat aineellisia todisteita entisistä omistus-, ystävyys- ja perhesuhteista ja niiden kautta tundralla elävien vastavuoroisuus jatkuu omistajasta huolimatta. Pienen pimeyden kuukausi ei kuvaa tätä uutta elämää: sen käytänteet, toimijat ja niiden väliset suhteet jäävät avoimiksi.

\section{Kahdentuvat tulkinnat}

Pienen pimeyden kuukausi on kirjoitettu marginaalista, pohjoisesta, ja se hyödyntää mahdollisuutta antaa ääni sekä vähemmistön että keskuksen näkökulmille ja pohtia, millainen hankala tila niiden välille syntyy. Kyseessä on romaani, joka palvelee sekä keskuksen tarvetta saada legitimaatio vallalleen että vähemmistön menneisyyden reflektiota. Romaanin kyläproosamaisuus ja kerronnassa käytetyt kyläproosan keinot hyödyntävät liikkeen tarjoamaa kriittisen keskustelun tilaa ja samalla osallistuvat sosialistisen realismin ohjelmaan, luovat nenetsit ja nenetsien kirjallisuuden osaksi imperiumin ideologisia prosesseja. Näissä pyrinnöissä teksti luo toistuvasti neuvostoliittolaisia kuvia, joissa paljon poroja omistavat ovat kulakkeja heille sopivine luonteenpiirteineen, nenetsit ovat jälkeenjääneitä ja heidän elämäntapansa on raskas, vaikka se voisi rationaalisten uudistusten myötä muuttua helpommaksi. Samalla Pienen pimeyden kuukaudessa pyritään kuitenkin kertomaan myös omassa asemassaan määrätietoisesti toimivista paimenista, joiden elämän keskus on tundralla ja kotakylässä, poronhoidossa siihen liittyvine konventioineen. Kuvat ovat toisinaan ristiriidassa, toisinaan ne esitetään rinnakkain, kun yksittäiset paimenet pohtivat, miten heidän tulisi menetellä. Nenetsien omakuvassa käsitykset ovat toisiinsa erottamattomasti liittyneitä. Hallitsevassa 
tulkintakehyksessä nenetsikuva muuttui Ledkovin romaanin myötä.

Sosialistisen realismin kuvastot eivät sovi nenetsien konventioihin, mutta niistä on neuvostoaikoina tullut kaikkien tuntemaa ja osa ihmisten arkea; konventiot ja kuvat on sovitettu toisiinsa. Esimerkiksi mielikuva paljon poroja omistavista nenetseistä kulakkeina sopii sosialistiseen realismiin, mutta nenetsien käsityksiin se sopii yhtä huonosti kuin mielikuva pienen pimeyden kuusta kielteisenä. Nenetsien näkökulmasta romaanin lähtöasetelmat ovat alusta alkaen vastoin paikallisia käsityksiä. Romaanin paratekstit toimivatkin kahdella tavalla: siinä missä ne todistavat romaanin kertovan sosialismin kehittämisestä yksille, toiset näkevät niissä ristiriidan. Romaanin vastakkaisten ja rinnakkaisten asetelmien välillä ei ole vain keskuksen ja periferian, vaan myös venäläisen ja nenetsikokemuksen ja tulkinnan ja nenetsien yhteisön sisälle rakentuvien erontekojen välisten tulkintojen välinen alue.

Olen kutsunut jännitettä välitilan ohella myös kahdentuvaksi tulkinnaksi, sillä porojen omistamiseen liittyvä kysymyksenasettelu jää ratkaisematta eikä sitä käsitellä avoimesti romaanissa. Jännitettä voi avata myös välisyyden (in-between) avulla etenkin, koska poroissa ja kolhoosissa ei ole kyse yksinkertaisesti omistamisesta, vaan laajemmasta ihmisten ja porojen välisestä suhteesta. Poropaimentolaisuus koostuu päivittäisestä toiminnasta tundralla porojen parissa ja siinä on kyse jatkuvasta vuorovaikutuksesta eläinten kanssa. Olen yllä tuonut esiin, miten tätä kuvataan romaanissa Jegorin toiminnan ja äänen avulla. Jokapäiväisen vuorovaikutuksen lisäksi poroja käytetään rituaaleissa, ystävyyden solmimisessa ja vahvistamisessa ja avioliitoissa. Tällaiset vastavuoroisuuteen liittyvät käytännöt asettuivat kollektivisoinnin myötä epävarmoiksi, eikä neuvostohallinto voinut ymmärtää, miten syvällisestä muutoksesta siinä oli kyse. Vastaavalla tavalla muutosta ja siihen liittyvää yhteisöllistä ja kulttuurista epävarmuutta on vaikea selittää venäläisyleisölle semminkin, kun 1970-luvulla Ledkovin romaanin kuvaamilla alueilla muutos oli jo tapahtunut ja poronhoidon käytännöt olivat sopeutuneet muutoksiin. Ihmiset toimivat jo kolhoosin sääntöjen puitteissa, mutta jatkoivat poropaimentolaista elämää tundralla: he elivät sellaisessa välitilassa, jossa poronhoidon toiminnan periaatteet oli ratkottu modernin, rationaalisuutta ja tehokkuutta korostavien periaatteiden avulla. Poropaimentolaisten konventioiden suhteen asiaa ei kuitenkaan ollut vielä ratkaistu, ja elämä tundralla rakentui edelleen vastavuoroisuudessa, ihmisten ohjaillessa poroja, joiden liikkeitä he itse seuraavat. Kolhoosissa nenetsit ovat sekä kehittyvän neuvostotalouden ja -yhteiskunnan alkuperäiskansajäseniä että poronhoitajana niin konventioiden mukaan toimivia paimenia kuin niitä vastaan rikkovia varkaitakin. Erilaisten ratkaisujen kuvaaminen - yksien vapaaehtoisuus, toisten vastahankaisuus ja kaikkien kohtaloon punoutuvat traagiset juonenkäänteet - on tapa kertoa pysyvästä ja ratkaisemattomasta ristiriidasta, jonka parissa nenetsit elävät.

\section{Viitteet}

$1 \mathrm{TN}$ viittaa tundranenetsiin. Tundranenetsinkieliset ilmaisut on translitteroitu sanojen kyrillisen ortografian mukaisesta kirjoitusasusta käyttäen kansallista venäjän translitterointiin tarkoitettua standardia, vaikka se ei kaikin osin toimikaan tundranenetsin yhteydessä. Valintaa tehdessä on pidetty mielessä, että analysoitu romaani on venäjänkielinen ja että translitteroinnin on syytä olla mahdollisimman selkeä lukijalle.

2 Käännökset venäjästä suomeen ovat kirjoittajan. 


\section{Lähteet}

Anderson, David (2014), Cultures of reciprocity and cultures of control in the Circumpolar North. Journal of Northern Studies 8: 2, 11-27.

Anderson, David (2017), Humans and animals in northern regions. - Annual Review of Anthropology 46, 133-149. http://www.annualreviews.org/doi/abs/10.1146/annurev-anthro-102116-041556

Anderson, David G., Jan Peter Laurens Loovers, Sara Asu Schroer \& Robert P. Wishart (2017), Architectures of domestication: on emplacing human-animal relations in the North. - Journal of the Royal Anthropological Institute 23, 398-418. https://doi.org/10.1111/1467-9655.12613_1

Ashcroft, Bill, Griffiths, Gareth, Tiffin, Helen (2002), The Empire Writes Back: Theory and Practice in Post-Colonial Literatures. [Online]. London and New York: Routledge.

Bhabha, Homi (1994), The Location of Culture. London and New York: Routledge.

Boele, Otto (1996), The North in Russian Romantic literature. Amsterdam, Atlanta: Rodopi.

Boele, Otto (2016), The North as a symbol of national identity in Russian culture. - Net Severa, no est'Severa: o mnogoobraziya ponyatiya "Sever" v Norvegii i Rossii. Toim. Kari Aga Myklebost, Jens Petter Nielsen, Victoria V. Tevlina, Alexey A. Komarov. Moskva: Lenand, 114-131.

Clark, Katerina (1981), The Soviet novel: History as ritual. Chicago: The University of Chicago Press.

Davydov, Vladimir (2014), Coming Back to the Same Places: the Ethnography of Human-reindeer Relations in the Northern Baikal region. - Journal of Ethnology and Folkloristics 8: 2, 7-32.

Dobrenko, Evgenij (2001), The Making of the State Writer: Social and Aesthetic Origins of Soviet Literary Culture. Stanford: Stanford University Press.

Frank, Susi K. (2010), City of the sun on ice: the Soviet (counter-) discourse of the Arctic in the 1930s - Arctic Discourses. Toim. Anka Ryall, Johan. Schimanski, and Henning Howlid. Wærp. Newcastle upon Tyne: Cambridge Scholars Publishing, 106-131.

Frank, Susi K. (2016), "Multinational Soviet Literature": The Project and Its Post-Soviet Legacy in Iurii Rytkheu and Gennadii Aigi. - Postcolonial Slavic Literatures After Communism. Toim. Klavdia Smola, Dirk Uffelmann. New York: Peter Lang, 191-217. https://doi.org/10.3726/978-3-653-06149-9

Frank, Susi K. (2017), Ice as a literary motive in Soviet Arctic modernities. - Arctic modernities: the environmental, the exotic, and the everyday. Toim. Heidi Hansson and Anka Ryall. Newcastle upon Tyne: Cambridge Scholars Publishing, 16-38.

Gaski, Harald (1999), The secretive text: yoik lyrics as literature and tradition. - Nordlit 5, 3-27. https://doi.org/10.7557/13.2142

Gillespie, David (1991), Ironies and legacies: village prose and glasnost. - Forum for Modern Language Studies 27:1, 70-84.

Golovnev, Andrei \& Osherenko, Gail (1999), Siberian Survival: The Nenets and Their Story. Ithaca: Cornell University Press.

Golovnev, Andrei (1995), Govorjaštšije kultury: traditsii samodijtsev i ugrov. Jekaterinburg: UrO RAN.

Kuikka, Eeva (2019), Muuttuva eläinsuhde Juri Rytheun Tuotannossa. - Idäntutkimus 26: 2, 3-18. https://doi.org/10.33345/idantutkimus.83668.

Kuikka, Eeva ja Lukin, Karina (2020), Eksoottista mutta modernia: Kieli, tieto ja identiteetti nenetsi- ja tšuktšikirjallisuudessa. - Kulttuurintutkimus 37(1-2): 102-115. https://journal.fi/kulttuurintutkimus/ article/view/98103

Kukulin, Ilja (2012), "Vnutrennjaja postkolonizatsija": Formirovanije postkolonialnogo soznanija v russkoi literature 1970-2000-h godov. - Tam, vnutri: Praktiki vnutrennei kolonizatsii v kulturnoi istorii Rossii. Toim. Aleksandr Etkind, Dirk Uffelman, Ilja Kukulin. Moskva: Novoe literaturnoje obozrenie, 846-909.

Kurki, Tuulikki (2018), Rajan kirjailijat: Venäjän Karjalan suomenkieliset kirjailijat tilan ja identiteetin kirjoittajina. Helsinki: Suomalaisen Kirjallisuuden Seura.

Lagunova, Olga (2007), Fenomen tvortšestva russkojazytšnyh pisatelei nentsev $i$ hantov poslednoi treti $X X$ veka. Tjumen: Izdatelstvo Tjumenskogo gosudarstvennogo universiteta.

Laptander, Roza (2014), Processes of Remembering and Forgetting: Tundra Nenets' Reminiscences of the 1943 Mandalada Rebellions - Sibirica: the journal of Siberian studies 13, 22-44. https:// doi.org/10.3167/sib.2014.130302

Ledkov, Vasili (1979), Mesjats maloi temnoty. Arhangelsk: Severo-zapadnoe knižnoe izdatelstvo.

Lee, Dennis (1974), Cadence, country, silence: writing in colonial space. - boundary 2 3:1, 151-168. 
Leiderman, Naum (2015), Russkojazytšnaja literatura - perekrestok kultur. - Filologitšeski klass $3: 41,19-24$.

Leiderman, Naum \& Lipovetski, Mark (2003), Sovremennaja russkaja literatura-1950-1990-e gody. Tom 2, 1968-1990. Moskva: Academia.

Lukin, Karina (2011), Elämän ja entisyyden maisemat. Helsinki: Suomalaisen Kirjallisuuden Seura.

Lukin, Karina (2020a), Soviet voices in Nenets literature. - Ways of being in the wolrd: studies on minority literatures. Toim. Johanna Laakso. Wien: Praesens verlag, 168-193.

Lukin, Karina (2020b), Recategorising an Arctic Hero: Entitlement and (Un)Tellability in a Soviet Drama. - Ethnologia Fennica 47(1), 33-56.

Lummaa, Karoliina (2010), Poliittinen siivekäs: lintujen konkreettisuus suomalaisessa 1970-luvun ympäristörunoudessa. Jyväskylä: Jyväskylän yliopisto.

McCannon, John (1998), Red Arctic: Polar Exploration and the Myth of the North in the Soviet Union, 1932-1939. New York: Oxford University Press.

Mihailov Aleksandr (1976), Severanaja tetrad: o rodnom kraje, o literature, o tovarištšah, o sebe. Arhangelsk: Severo-zapadnoe knižnoe izdatelstvo.

Nichols, Johanna (1993), Stereotyping Interethnic Communication: The Siberian Native in Soviet Literature. - Between heaven and hell: The Myth of Siberia in Russian Culture. Toim. Galya Diment \& Yuri Slezkine. New York: Palgrave Macmillan, 185-214.

Ogryzko, Vjatšeslav (2003), Samojed - slovo russkoe. Nenetskaja literatura. Toim. Vjatšeslav Ogryzko. Moskva: Literaturnaja Rossija, 29-30.

Parthé; Kathleen F. (1992), Russian village prose: the radiant past. Princeton: Princeton University Press.

Perkiömäki, Mika (2018), Matka hukutetulla joella. Ympäristöoikeudenmukaisuus Valentin Rasputinin 1970-luvun jokiproosassa. - Veteen kirjoitettu: veden merkitykset kirjallisuudessa. Toim. Markku Lehtimäki, Hanna Meretoja, Arja Rosenholm. Helsinki: Suomalaisen Kirjallisuuden Seura, 305-332.

Ponomarev, Boris Semenovitš (1982), Literaturnyj Arhangelsk: Sobytija, imena, fakty 1920-1980. Arhangelsk: Severo-zapadnoe knižnoe izdatelstvo.

Pošatajeva, Alla (1988), Literatury narodov Severa. Moskva: Nauka.

Razuvalova, Anna (2015), Pisateli-“derevenšiki”: Literatura i konservativnaja ideologija 1970-h godov. Moskva: Novoe literaturnoe obozrenie.

Rojola, Lea (2015), ... sukkajalka, kalppinokka, tuuliturpa ...Nils-Aslak Valkeapään porojen poetiikka. - Kirjallisuudentutkimuksen aikakauslehti AVAIN 3, 86-104

Sergejev, Mihail (1955), Nekapitalistitšeski put razvitija malyh narodov Severa. Moskva: Institut etnografii im. Mikluho-Maklaja.

Slezkine, Yuri (1994), Arctic mirrors: Russia and the small peoples of the North. Ithaca: Cornell University Press.

Spivak, Gayatri Chakravorty (1993), Can the Subaltern Speak? - Colonial Discourse and Postcolonial Theory: A Reader. Toim. Patrick Williams \& Laura Chrisman. New York: Routledge, 66-111.

Stammler, Florian (2005), Reindeer nomads meet the market: Culture, property and globalisation at the "end of the land". Münster: LIT.

Stammler, Florian (2010), Animal diversity and its social significance among arctic pastoralists. - Good to eat, good to live with: nomads and animals in northern Eurasia and Africa. Toim. Florian Stammler \& H. Takakura. Sendai: Tohoku University, 215-243.

Stépanoff, Charles, Charlotte Marchina, Camille Fossier \& Nicolas Bureau (2017), Animal autonomy and intermittent coexistencies: North Asian modes of herding. - Current Anthropology 58:1, 57-81.

Tuisku, Tuula (1999), Nenetsien ankarat elämisen ehdot tundralla ja kylässä: poronhoidon sopeutumisstrategiat ja delokalisoitumisprosessi Nenetsiassa. Rovaniemi: Lapin yliopisto.

Turoma, Sanna \& Waldstein, Maxim (2013), Empire and Space: Russian and the Soviet Union in Focus. - Empire De/Centered: New Spatial Histories of Russia and Soviet Union. Toim. Sanna Turoma \& Maxim Waldstein. London \& New York: Routledge, 19-56.

Vallikivi, Laur (2005), Two Wars in Conflict: Resistance among Nenets Reindeer Herders in the 1940s - Studies in Folk Culture V, 14-54.

Veter, Andrei (2003), Kniga, prišedštšaja iz serdca. Toim. Vjatšeslav Ogryzko. Moskva: Literaturnaja Rossija, 26-28. 